\title{
Metodologias Pedagógicas Ativas sobre o Pensamento de Albert Einstein Aplicadas em Modelagem na Disciplina de Vibrações Mecânicas da Engenharia
}

\author{
DOI: 10.37702/2175-957X.COBENGE.2021.3746
}

Rafael de Carvalho Puglisi - rfpuglisi@usp.br

Escola Politécnica da USP

Avenida Caminho do Mar 1680

09610-000 - São Bernardo do Campo - SP

Luara Maria de Freitas Lobo - luara.lobo@unifesp.br

Universidade Federal de São Paulo

Avenida Santos Dumont 1350

02012-010 - São Paulo - SP

Resumo: $O$ presente trabalho objetiva estudar as estratégias de ensino adotadas na Disciplina de Vibrações Mecânicas na graduação de Engenharia Mecânica pela análise do Plano Pedagógico do Curso (PPC) e análise comportamental dos discentes através de relato de professores da Escola Politécnica da USP, Centro Universitário FEI e outras IES, utilizando como referência o pensamento pedagógico de Albert Einstein. Trata-se de relatar as metodologias pedagógicas propostas que permitem compreender a evolução do ensino-aprendizagem dos discentes na interpretação da modelagem de sistemas dinâmicos, principalmente, na transição da estática para a dinâmica, que tem sido um dos maiores desafios enfrentados pela disciplina devido à contextos culturais e educacionais de entendimento do movimento, da estabilidade e controle. A escolha de Albert Einstein é devida suas contribuições científicas, sua carreira docente voltada para a compreensão da dinâmica dos corpos e a relevância de suas reflexões na construção de um pensamento pedagógico. O pensamento educacional de Einstein faz crítica ao autoritarismo no ensino, ressalta a importância da autonomia e criatividade na construção do saber e destaca a relevância ético-política da educação. Guiado por esse pensamento, o estudo propõe metodologias ativas utilizando a imaginação do aluno como ferramenta de ensino. Conclui-se que proporcionar um ambiente com metodologias que estimulem a imaginação e consequente criatividade do aluno geram baixos custos e são eficientes na diplomação de profissionais mais aptos a compreenderem a disciplina de vibrações, 


\section{CCOBENGE

assim como na formação de cidadãos conscientes de sua responsabilidade ético-política na construção de uma a sociedade justa, equânime e fraterna.

Palavras-chave: Vibrações Mecânicas. Metodologias Ativas. Albert Einstein. Imaginação na Engenharia. Ética-política na Engenharia. 


\section{METODOLOGIAS PEDAGÓGICAS ATIVAS SOBRE O PENSAMENTO DE ALBERT EINSTEIN APLICADAS EM MODELAGEM NA DISCIPLINA DE VIBRAÇÕES MECÂNICAS DA ENGENHARIA}

\section{INTRODUÇÃO}

O conhecimento do comportamento dinâmico dos sistemas mecânicos e seus componentes é essencial na formação dos engenheiros mecânicos. O ingresso dos alunos na graduação em engenharia traz consigo, em geral, raízes culturais e educacionais voltadas para um entendimento universal da estabilidade através da estática (INMAN, 2014). A transição para a percepção da dinâmica na física afeta a maneira com que os alunos enxergam a estabilidade, e tem sido dificultoso conseguir descrever matematicamente através do processo de modelagem o movimento e interação dos corpos. Também é comum ouvir a expressão "Você já parou para pensar", ou seja, essa ideia de que o pensamento esteja estagnado fortalece a cultura do pensar como algo ocioso e estático. Essas relações culturais da percepção do movimento e do pensar tem tornado difícil a compreensão no curso de Vibrações Mecânicas (DEN HARTOG, 1972), principalmente, na transição das análises dos fenômenos estáticos para a análise dinâmica dos corpos. Entre os maiores desafios encontrados na disciplina de Vibrações Mecânicas e Sistemas Dinâmicos e Controle é a modelagem dinâmica dos sistemas $(\mathrm{HATCH}, 2001)$. Sabemos que o estudo dinâmico da física se inicia no Ensino Básico e, que durante esse período percorre-se pela cinemática e as leis fundamentais da dinâmica aplicadas à exercícios teóricos. Poucas escolas tratam esse aprendizado com laboratórios e aulas lúdicas contemplativas das ciências da natureza, muitas vezes decorrem dos métodos tradicionais, passivos e memorizados; ambiente que não favorece o desenvolvimento do aluno.

Albert Einstein, é um dos maiores cientistas conhecidos do século $X X$. Sua contribuição científica é genuína e vasta, especialmente pela Teoria da Relatividade. Aprofundou-se no estudo da dinâmica e relação dos corpos. Além de um genial físico, Einstein sempre teve interesse pelo universo humano (SPINOZA, 2003) foi um pensador implicado com a democracia, um educador comprometido com o respeito ao aprendiz e com a defesa de que o desenvolvimento discente fosse autônomo e criativo. Suas concepções educacionais democráticas representam uma mudança em relação ao ensino tradicional, tendo como base a liberdade/autonomia, igualdade/equidade e fraternidade/compaixão (MEDEIROS \& MEDEIROS, 2006). O pensamento educacional de Einstein potencializa a formação do ser humano e vai ao encontro do cenário educacional atual, tendo em vista as demandas de modificações no ensino-aprendizagem, gerando o desenvolvimento de metodologias ativas na educação (MITRE et al., 2008). Einstein ressalta críticas à centralização do ensino no professor, à passividade e memorização mecânica de conteúdos pelo aluno e ressalta a importância de a relação professor-aluno ser mais humana para propiciar um ambiente onde o discente tenha autonomia para criar sem restrições e punições, considerando o conhecimento uma construção. A cultura, o espírito crítico, a ética e a 
consciência social, seriam aspectos que deveriam permear o processo de ensinoaprendizagem, priorizando a criatividade e a imaginação.

Segundo Runco (2007) o ser humano tem potencial para ser criativo, porém, nem todas as pessoas realizam esse potencial, por não terem oportunidades de desenvolvê-lo. A escola é um dos ambientes de maior influência na vida de uma pessoa, os profissionais que estão inseridos nesse ambiente têm papel fundamental para estimular o potencial criativo do ser humano. Alencar e Fleith (2003) destacam a ênfase na reprodução do conhecimento, na memorização de ensinamentos e a pouca ênfase à imaginação como elementos que inibem o desenvolvimento e a expressão da capacidade de criar. A imaginação é intrínseca ao ser, todo o ser humano imagina, porém ela precisa ser praticada. Para Análise do Comportamento, uma abordagem da Psicologia, a imaginação é entendida como comportamento encoberto. Segundo Skinner (1993) imaginar é um comportamento, porém, não há acesso social a ele e, por esse motivo, recebe o nome de encoberto. Por ser um comportamento encoberto, a imaginação muitas vezes é reprimida e ignorada socialmente, inclusive nas escolas. Imaginar, como um comportamento, se modifica pela experiência, isto é, quando estimulada e guiada é aprimorada, tornando-a uma ferramenta valiosa no ensino. Estudos mostram que no momento em que se emprega a prática da imaginação, há alterações musculares (LASSEN, et al., 1978) e do sistema nervoso autônomo (DESCHAUMES, et al., 1991), dados que reforçam a importância de sua utilização no ensino.

Diante da dificuldade no ensino da disciplina de vibrações mecânicas na engenharia mecânica e a crítica de Albert Einstein ao ensino tradicional, onde a aprendizagem é centrada no professor, não favorecendo o desenvolvimento da criatividade e imaginação do aluno, levantou-se as seguintes questões: os planos de ensino de engenharia mecânica atual seguem os pensamentos educacionais propostos por Einstein? Como podemos aproximar o pensamento educacional de Albert Einstein com a prática da disciplina de vibrações na graduação de engenharia mecânica? O caminho proposto para essa aproximação seria proporcionar um ambiente educacional onde a imaginação seja estimulada e guiada. Tendo em vista que para desenvolver o potencial criativo no ser humano, a imaginação é um recurso, e é um dos menos explorados nas escolas, especialmente, com jovens e adultos.

\section{METODOLOGIA}

O objetivo do curso de Engenharia Mecânica em disciplinas de Vibrações Mecânicas é permitir que, ao seu final, os alunos entendam como as vibrações nesses sistemas e componentes podem ser analisadas por modelos com 1 ou 2 Graus de Liberdade e como a extensão para um número maior de Graus de Liberdade é natural. Porém, a realidade se manifesta diferente e os alunos tem alto grau de dificuldade de compreensão. Para essa disciplina, o conhecimento do comportamento dinâmico dos sistemas mecânicos e seus componentes é essencial na formação do engenheiro mecânico. A presente pesquisa visa aprimorar as estratégias pedagógicas e ativas guiada pelo pensamento de Einstein utilizando a imaginação na compreensão da disciplina. Serão abordadas as ciências da natureza e o pensamento educacional de Einstein seguindo o seguinte caminho (MEDEIROS \& MEDEIROS, 2006): a crítica ao 
autoritarismo, a autonomia, a questão da criatividade e a relevância ético-política da educação.

\title{
2.1 A crítica ao autoritarismo
}

Uma das principais críticas de Einstein à educação se refere aos métodos de ensino-aprendizagem baseados no autoritarismo e na memorização mecânica de conteúdo, método predominante até hoje em escolas e universidades do Brasil (BRANDÃO, 2007). Einstein faz uma comparação a repetições mecânicas do trabalho humano limitado e a ausência de criatividade - alienante - ao ensino tradicional, onde a valorização da criatividade e independência do pensamento são inexistentes. $O$ discente obtém o resultado por processos mecânicos de memorização, tornando-o alienado do produto intelectual, os quais são prejudiciais à formação do aprendiz:

\begin{abstract}
$\mathrm{Na}$ verdade, é quase um milagre que os métodos modernos de instrução não tenham exterminado a sagrada sede de saber, pois essa planta frágil da curiosidade científica necessita, além de estímulo, especialmente de liberdade; sem ela, fenece e morre. É um grave erro supor que a satisfação de observar e pesquisar pode ser promovida por meio da coerção e da noção do dever. (EINSTEIN, 1982)
\end{abstract}

\section{Discussão e Estratégia}

A rigidez e o conservadorismo da educação favorecem a obediência e dificulta o aluno a enxergar a liberdade (dinâmica) dos corpos. A modelagem precisa ser ensinada de forma dinâmica, que liberte o ser humano da interação rígida do aprendizado. Podemos considerar a liberdade mencionada por Einstein como uma maneira de transformar a percepção do meio, da pesquisa e do laboratório. Nesse contexto, cada aluno deve ser estimulado a romper as fronteiras do que é um laboratório, e desenvolver seu próprio ambiente laboratorial, seja na sua casa, espaços públicos e comunitários. O autoritarismo diz respeito a dinâmica social, contrapondo-se a liberdade de expressão e democracia. A metodologia mecanizada pode trazer mais estagnação a criatividade do discente, porém, pode ser uma alternativa para que ali seja aplicada a imaginação, visto que o conhecimento técnico já foi adquirido e ele está latente. A centralização do conhecimento no professor, enrijece a autonomia do aluno, por isso também precisa ser trabalhada. Estratégias:

- Inversão de papéis: o discente propor aulas, ministrá-las, corrigir provas e atividades (próprias e de outros colegas), assim como explorar outros ambientes laboratoriais para além da sala de aula. Para que os alunos possam enxergar o movimento dos corpos é necessário que ele transite e experimente diferentes papéis dentro e fora da sala de aula.

- Grupos e brainstorming são técnicas novas para as disciplinas de Vibrações Mecânicas, além da tradicional como as expositivas.

- Desenho: solicitar que os alunos façam um desenho que represente o conteúdo que tiveram em aula. $O$ ato de desenhar utilizando diferentes cores faz com que os alunos explorem a imaginação e criem algo próprio através do lúdico. Os discentes saem do modo passivo e passam a ser ativos no processo, no movimento de transformar o conteúdo teórico que aprenderam, para o papel em forma de imagem. 
Essa conduta para os alunos é fundamental também para que compreendam e exercitem seu papel em tomada de decisões. Einstein sugere uma postura por parte dos professores que permita que aluno tenha liberdade e autonomia, possibilitando assim o entendimento dos fenômenos dinâmicos. Ele acreditava na possibilidade do discente trilhar seu caminho para solução das questões, construindo o próprio conhecimento.

\subsection{A autonomia do estudante e a questão da criatividade}

Para Einstein a construção do conhecimento deve ser articulada a uma relação professor-estudante mais humana e aberta, onde a cultura, o espírito crítico, a ética e a consciência social, são aspectos que devem permear o processo de ensino aprendizagem, priorizando a criatividade, a imaginação e a intuição.

(...) para ficar satisfeito, o homem deve também ter a possibilidade de desenvolver as suas capacidades intelectuais e artísticas, sem limites restritivos, segundo as suas características e aptidões pessoais. (EINSTEIN apud MEDEIROS e MEDEIROS, 2006)

A autonomia e a dignidade de cada indivíduo devem ser respeitadas no ato de ensinar-aprender, essência de uma abordagem progressiva e base de uma educação que enxerga o ser humano como construtor de sua própria história (COSTA e SIQUEIRA-BATISTA, 2004), com potencial para o desenvolvimento de sua criatividade. Neste raciocínio, é possível aproximar as concepções de Einstein às reflexões de pensadores de vanguarda na Educação, como John Dewey (1970) e Paulo Freire (2006).

\section{Discussão e Estratégia}

A engenharia na disciplina de Vibrações Mecânicas não precisa ser rígida, é importante que os alunos construam a percepção da criatividade, da imaginação e liberdade. A liberdade está diretamente vinculada com a ideia de movimento. Os números complexos ou imaginários dizem por si só que somente na imaginação existem áreas negativas, ou seja, o mundo visível e material precisa ser um mundo imaginário também. É importante que nessas disciplinas a modelagem esteja correlacionada com o criativo e imaginário representando o mundo físico. Se não há percepção que os corpos estão em movimento, consequentemente não há percepção da própria liberdade. Dessa forma, a imaginação precisa ser guiada. Sabe-se que a rotina diária dos alunos, fruto da sociedade moderna industrial, muitas vezes não favorece a absorção dos conteúdos programáticos, principalmente quando esses conteúdos reforçam a mecanização do pensamento. Portanto, essa exaustão dificulta a inserção de metodologias ativas na graduação. Estratégias:

- Imaginação guiada: música escolhida pelo professor, que solicita que os alunos fechem os olhos e, através de um roteiro previamente elaborado, guia a imaginação dos alunos. Posteriormente, o aluno escreve ou compartilha o que imaginou e pensou. O intuito, além de ser uma preparação para a aula, é que o aluno consiga tornar consciente seus pensamentos e imaginação, possibilitando que o aluno tenha reflexões mais profundas e autonomia. 
- Montar estruturas de galhos: com galhos de plantas e árvores os discentes criam uma estrutura. Nessa atividade o aluno estará estimulando seu potencial criativo, percebendo o equilíbrio dos objetos e o seu próprio equilíbrio.

- Pêndulo humano: atividade corporal realizada em trio, os alunos ficam de pé, dois discentes se posicionam um em cada extremidade, e o terceiro aluno se posiciona no meio. $O$ discente que estará no meio irá movimentar o corpo em direção aos alunos das extremidades que irão empurrá-lo com as mãos, como se fosse um pêndulo. $O$ intuito dessa atividade é que o aluno consiga sentir sua frequência natural e ressonância.

\title{
2.3 A questão da relevância ético-política da educação
}

Segundo Einstein, um dos principais problemas encontrados nas escolas é a especialização precoce, o autor ressalta a importância da formação técnica, reconhecendo-a como necessária, porém insuficiente para a formação do discente:

\begin{abstract}
Quero rebater a ideia de que a escola deve ensinar diretamente o conhecimento e as habilidades que a pessoa terá de usar mais tarde diretamente na vida. As exigências da vida são demasiadamente multiformes para que esse aprendizado específico na escola pareça possível. Ademais, parece-me censurável tratar o indivíduo como uma ferramenta inanimada. A escola deve ter por finalidade que o jovem a deixe como uma personalidade harmoniosa, não como um especialista. (EINSTEIN apud MEDEIROS e MEDEIROS, 2006)
\end{abstract}

Nesse trecho o autor destaca a importância do desenvolvimento das "competências" ético-políticas pelo individuo, no sentido do aprendizado da convivência em sociedade, construindo uma relação justa e fraterna. O estudante tem o direito de se realizar enquanto indivíduo/cidadão; o ambiente educacional precisa fornecer a possibilidade de ação e de transformação, para benefícios próprios e sociais. A diferença entre a educação e o mero ensino, para Einstein, está na importância ética e política. O ambiente escolar deve ser prazeroso, proporcionando o desenvolvimento de indivíduos autênticos e éticos para a convivência social.

\section{Discussão e Estratégia}

Ao realizar uma comparação ontológica do ser humano com a ciência da natureza, o ser humano precisa transcender sua forma humana, percebendo sua condição de objeto (corpo) e as leis fundamentais da natureza aplicadas em si. A imaginação é essencial para compreender a vulnerabilidade, visto que a imaginação liberta da condição humana e de controle. Encontrar a semelhança em outros objetos faz com que os seres humanos não se limitem a essa condição. Para entender os fenômenos dinâmicos vibratórios: ressonância, estabilidade e controle, uma prática ativa de imaginar possibilita compreender o que é controlar o equilíbrio. Estratégias:

- Imaginação guiada: o professor conduzirá a atividade, através de um roteiro previamente elaborado, onde o aluno imaginará sua existência de outra forma no planeta, exemplo, uma árvore balançando. O professor deve inserir no roteiro estímulos visuais, táteis, auditivos e olfativos para ficar mais próximo dos sentidos do aluno. 
- Contação de histórias: contar histórias que estimulem a imaginação do aluno, exemplos histórias da criação do universo: mitologia grega, egípcia e indígena. Nessas mitologias aparecem diferentes representações nas formas de existência.

O intuito de ambas estratégias é que o discente exercite sua imaginação e capacidade criativa para sentir sua existência de outras formas e entender os fenômenos dinâmicos vibratórios.

Em relação à disciplina de vibrações, o equilíbrio energético e dinâmico é fundamental para compreender a modelagem. Demonstrar com exemplos políticossociais, por exemplo, o equilíbrio da balança da justiça, ajuda a imaginar os conceitos da disciplina e como podem ser aplicados no cotidiano. A democracia é constituída pelo equilíbrio da diversidade, ou seja, por diversas forças atuantes, resultando na justiça, Figura 1. O princípio da estabilidade dinâmica é compreender através do movimento quais interferências e sintonias podem ser realizadas para dinamicamente compreendermos o equilíbrio. A modelagem que o aluno faz do meio físico é requisito essencial para compreender a transferência energética por meio da ressonância. A conduta apresentada por Einstein permite que o aluno construa sua percepção sobre como o entendimento dos fenômenos dinâmicos estão vinculados diretamente com a liberdade, justiça e autonomia de cada aluno.

Figura 1: Têmis - Símbolo da Justiça.

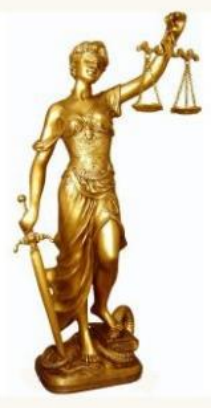

Fonte: Supremo Tribunal Federal, 2020

\section{ANÁLISE DOS PPC'S DAS IES}

\subsection{Objetivos}

Um dos objetivos deste trabalho é analisar o Plano Pedagógico de Curso (PPC) da Disciplina Vibrações Mecânicas entre a Escola Politécnica da USP e o Centro Universitário da FEI, utilizando como referência os pensamentos de Albert Einstein, relatos dos professores dessa disciplina e de disciplinas semelhantes na Tabela 1.

Tabela 1: Objetivos - PPC da Escola Politécnica da USP e do Centro Universitário FEI

\section{Escola Politécnica da USP (2015)}

- Aprendizado de noções básicas de vibrações em sistemas mecânicos.

- Capacitação em modelagem e análise de sistemas com um ou mais graus de
Centro Universitário FEI (2018)

- O conhecimento do comportamento dinâmico dos sistemas mecânicos e seus componentes

- Entendam como as vibrações nesses sistemas e componentes podem ser analisadas por modelos com 1 ou 2 Graus de Liberdade 
liberdade mecânicas.

- Familiarização com sistemas de sujeitos

a

excitações supressão de vibração. Introdução à vibração de sistemas contínuos.

Fonte: Autor, 2020.

Os objetivos em ambas estão detalhados do ponto de vista dos conhecimentos técnicos adquiridos, porém, as habilidades estão incompletas e as atitudes-valores esperados não constam no PPC. O pensamento de Einstein pode ser introduzido através de exercícios de imaginação individual e coletiva para o desenvolvimento de habilidades. Essa estratégia ativa na disciplina provoca no aluno empoderamento criativo na resolução de problemas e percepção de como aplicá-los na sua realidade. Nota-se que as ideias educacionais de Einstein poderiam ser aplicadas nas habilidades e competências através de posturas que devem ser esperadas para um engenheiro(a) tais como; traquejo aritmético e algébrico, trabalhar em equipe e comunicação. As práticas imaginárias buscam alcançar nos alunos a percepção destas características, o fortalecimento da sua autonomia e elevação da criatividade. A ético-política do pensamento de Einstein é atingida através de exercícios de equilíbrio (balança) e organizacionais de gestão e governança (equilíbrio dos poderes) para alcançar justiça e compreensão nos valores-atitudes esperados que dizem respeito à, por exemplo, valorização a importância da formação básica para o engenheiro, assumir responsabilidades e adotar posturas.

\subsection{Programa}

Os programas das duas IES estão sucintos e sólidos no sentido do conhecimento técnico adquirido o que condiz com programas tradicionais da disciplina de Vibrações. Ao comparar os programas, percebe-se que o conteúdo apresentado possui alto grau de semelhança, exceto o laboratório prático. Pode-se notar que na Escola Politécnica da USP há um aprofundamento em algumas abordagens laboratoriais discutidos na Tabela 2.

Tabela 2: Programa - PPC da Escola Politécnica da USP e do Centro Universitário FEI.

\begin{tabular}{|c|c|}
\hline Escola Politécnica da USP & Centro Universitário FEI \\
\hline $\begin{array}{l}\text { - } \quad \text { Balanceamento e velocidade crítica de rotores. } \\
\text { - } \quad \text { Vibrações de sistemas com um grau de } \\
\text { - } \quad \text { Resposta a excitações harmônicas. } \\
\text { - } \quad \text { gibrações forçadas devido a excitações } \\
\text { - } \quad \text { Transmissão e isolamento de vibrações. } \\
\text { - } \quad \text { Projetóes de supressores de vibração. } \\
\text { - } \quad \text { Sistemas com vários graus de liberdade. } \\
\text { - Vibrações em sistemas contínuos. }\end{array}$ & 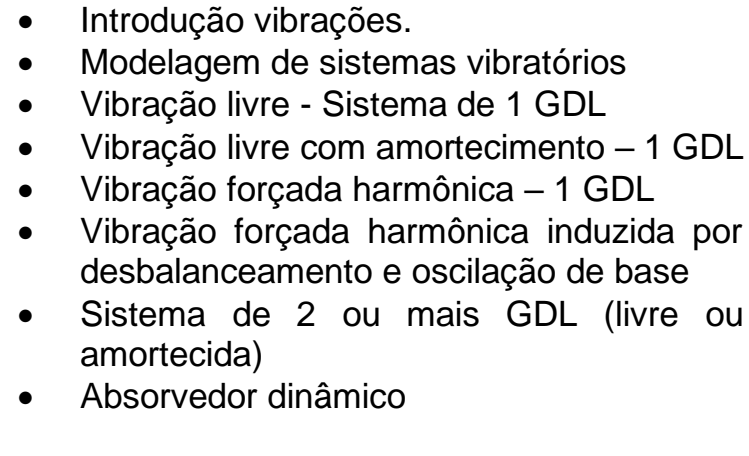 \\
\hline
\end{tabular}
Fonte: Autor, 2020.

Na perspectiva técnica novamente, o programa atende de forma precisa. Porém, é necessário ressaltar a importância de utilizar as metodologias ativas na compreensão dos conteúdos abordados. 


\subsection{Metodologia Adotada/Cronograma}

Em relação a metodologia adotada para ambas IES, as aulas expositivas são consolidadas e amplas. Entretanto, o modelo segue rígido e repetitivo, principalmente no que se refere as atividades discentes tais como: exercícios de aplicação, em classe e em casa; utilização de programas computacionais para construção de gráficos ou simulação de sistemas. A metodologia de rever os assuntos, pode trazer mais estagnação à criatividade do aluno, mas também pode ser uma alternativa para que ali seja aplicada a imaginação, visto que o conhecimento técnico já foi adquirido. Apesar das metodologias e programas estarem bem descritos para o conhecimento técnico, faltou destrinchar os conteúdos pautados em estratégias ativas. O pensamento educacional segundo Einstein pode ser empregado na proposta de reduzir a centralização do conhecimento no professor e potencializar a autonomia do aluno em perceber o conhecimento técnico como algo construído dentro da sua realidade. A dificuldade em entender os fenômenos dinâmicos está também em perceber o professor como referencial absoluto e inerte, ou seja, o centro de todo o conhecimento. Sendo assim, é necessário que a autonomia e criatividade sejam ferramentas para perceber o movimento.

\section{Aulas Expositivas}

Nas metodologias adotadas não encontramos as questões ético-políticas. Por exemplo, ao falar de elementos rotativos e do fenômeno da centrifugação, é possível fazer uma analogia com fenômenos de gentrificação devido a dinâmica social. O pensamento de Einstein poderia ser aplicado para que os alunos entendessem não só a mecânica dos objetos, mas a mecânica social. Por isso, a imaginação é uma ferramenta fundamental. A justificativa é que a postura centralizada no professor, além de gerar sua sobrecarga de trabalho, faz com que o aluno perceba apenas o centro, sentindo-se marginalizado ou inferiorizado. Imaginar desperta sua autonomia, liberdade e valorização do seu conhecimento. Em outras palavras, o modelo rígido e centralizado através apenas do conhecimento técnico faz com que o aluno fique inerte e estagnado. É uma questão ético-política e libertadora a imaginação na realidade do aluno para que ele se perceba em movimento e como parte de movimentos sociais, ou seja, a comparação com os modelos físicos e matemáticos estimula o aluno perceber sua realidade e contexto social que se encontra.

\section{Aulas Práticas}

A Escola Politécnica da USP apresenta um grande avanço no ensinoaprendizagem nas metodologias ativas por propor em seu programa aulas práticas de laboratórios. Entretanto, as aulas práticas ainda consistem exclusivamente nas observações e resultados conhecidos, exclusivos a ambientes controlados. As ideias de Einstein tendem no sentido de libertar os contornos territoriais do que se entende por laboratório. É fundamental nesse contexto que as aulas práticas sejam estendidas para estratégias que transcendam os recursos materiais e de infraestrutura. Os laboratórios são essenciais para o curso de engenharia e não somente laboratórios de ensaios, mas laboratórios como ambientes laboratoriais estendidos (ruas, parques, etc) e sociais da realidade socioeconômica dos alunos. Para um ambiente com 
elevada quantidade de alunos a imaginação guiada é mais eficiente, tanto individual quanto em grupo, e requer menos investimento de infraestrutura. Os ambientes virtuais também, nesse caso, se tornam mais eficientes, pois podem ser uma extensão da imaginação. Logo, o aluno desenvolve sua autonomia, confiança, motivação e protagonismo.

\section{CONCLUSÕES}

Culturalmente o modelo educacional adotado no Brasil em grande parte das escolas e universidades ainda é pautado na educação tradicional: rígida, inflexível, com o professor no centro e aulas expositivas. Ambiente que favorece 0 comportamento passivo e previsível por parte dos alunos, que esperam que a resolução de problemas venha pelo professor. As dificuldades encontradas pelos alunos, por exemplo, na modelagem dinâmica dos sistemas na disciplina de Vibrações Mecânicas e Sistemas Dinâmicos e Controle na graduação de Engenharia Mecânica é consequência da metodologia pedagógica que não potencializa a criatividade e imaginação dos discentes. A disciplina de Vibrações, para ter um alcance eficaz, precisa de ambientes laboratoriais estendidos para seu entendimento. Proporcionar um ambiente com metodologias ativas que estimulem a imaginação e consequente criatividade do aluno, geram custos menores de infraestrutura, tornam-se mais eficientes tanto na diplomação de profissionais mais aptos a compreenderem a disciplina de vibrações mecânicas quanto a utilizar recursos tecnológicos assim como, na formação de cidadãos conscientes de sua responsabilidade ético-política em uma sociedade mais justa, equânime e fraterna. Em momentos de transições, no qual as transformações no âmbito da educação parecem se tornar cada vez mais difíceis, rever os processos de ensino-aprendizagem passam a requerer reflexão ainda mais constante e profundas. Pensar pedagogicamente como Einstein, principalmente no ensino das ciências da natureza, aumentará a probabilidade de êxito na criação de espaços educacionais amplos e baratos e, consequentemente, na formação de profissionais com autonomia para criar, tomar decisões e utilizar recursos tecnológicos. Além disso, cidadãos conscientes de suas responsabilidades éticopolítica na construção de uma sociedade mais fraterna, democrática, justa e equânime.

\section{REFERÊNCIAS}

ALENCAR, Eunice Maria Lima Soreano; FLEITH, Denise de Souza. Criatividade: múltiplas perspectivas. 3ํo edição, Brasília: EdUnB, 2003.

BRANDÃO, Zélia. A crise dos paradigmas e a educação. 10 edição, São Paulo: Cortez, 2007.

COSTA, C. R. B. S. F.; SIQUEIRA, B. R. As teorias do desenvolvimento moral e o ensino médico: uma reflexão pedagógica centrada na autonomia do educando.

Revista Brasileira de Educação Médica, v. 28, n. 3, p. 242-250, 2004. 
DEN HARTOG, Jacob P. Vibrações mecânicas. Edgard Blücher, 1972.

DESCHAUMES, C.M; DITTMAR, A; VERNET, M.E; 1. Relationship between mental imagery and sporting performance. Behavioural Brain Research, v.45, p. 29-36, 1991.

DEWEY, John. Liberalismo, liberdade e cultura. São Paulo: Nacional, 1970.

EINSTEIN, Albert. Notas autobiográficas. Rio de Janeiro: Nova Fronteira, 1982.

FREIRE, Paulo. Pedagogia da autonomia: saberes necessários à prática educativa. 33ª edição, São Paulo: Paz e Terra, 2006.

HATCH, Michael R. Vibration simulation using MATLAB and ANSYS. $1^{\text {a }}$ edição: Chapman \& Hall, 2001.

INMAN, Daniel J. Engineering Vibration. 4를 edição: Pearson 2014.

LASSEN, N.A; INGVAR, D.H ; SKINHOJ, E. Brain function and blood flow. Scientific American. v. 239, n.1, p. 62-71, 1978.

MEDEIROS, Alexandre; MEDEIROS, Cleide. Einstein e a educação. São Paulo: Livraria da Física. 2006.

MITRE, S. M., SIQUEIRA-BATISTA, R., GIRARDI-DE-MENDONCCA, J. M., MORAISPINTO, N. M., MEIRELLES, C. A. B., PINTO-PORTO, C., MOREIRA, T., HOFFMANN, L. M. A. Metodologias ativas de ensino aprendizagem na formação profissional em saúde: debates atuais. Ciência \& Saúde Coletiva, v.13, p.2133 2144, 2008.

RUNCO, Mark. Creativity, theories and themes: research, development, and practice. San Diego: Elsevier, 2007.

SKINNER, Burrhus Frederic. Sobre Behaviorismo. São Paulo: Cultrix, 1993.

SPINOZA, Baruch. Ética - demonstrada à maneira dos geômetras. São Paulo: Martin Claret, 2003. 


\title{
ACTIVE PEDAGOGICAL METHODOLOGIES ABOUT ALBERT EINSTEIN'S THOUGHTS APPLIED IN MODELING IN THE MECHANICAL VIBRATION DISCIPLINE OF ENGINEERING
}

\begin{abstract}
The present work aims to study the teaching strategies adopted in the Mechanical Vibrations Discipline in the Mechanical Engineering undergraduate program by analyzing the Pedagogical Plan Course (PPC) and behavioral analysis of the students through the report of professors at the Polytechnic School of USP, Centro Universitário FEl and others, using Albert Einstein's pedagogical thinking as a reference. It is about reporting the proposed pedagogical methodologies that make it possible to understand the evolution of students' teaching-learning in the interpretation of the modeling of dynamic systems, mainly in the transition from static to dynamic, which has been one of the greatest challenges faced by the course due to the cultural and educational contexts of understanding movement, stability and control. Albert Einstein's choice is due to his scientific contributions, his teaching career focused on understanding the dynamics behavior and the relevance of his reflections in the construction of pedagogical thinking. Einstein's educational thinking criticizes authoritarianism in teaching, emphasizes the importance of autonomy and creativity in the construction of knowledge and highlights the ethical-political relevance of education. Guided by this thought, the study proposes active methodologies using the student's imagination as a teaching tool. It is concluded that providing an environment with methodologies that stimulate student's imagination and consequent creativity generate low costs and are efficient in the qualification of professionals more able to understand the discipline of vibrations, as well as in the formation of citizens aware of their ethical-political responsibility in the building of a just, equitable and fraternal society.
\end{abstract}

Keywords: Mechanical Vibrations. Active Methodologies. Albert Einstein. Imagination in Engineering. Political ethics in engineering. 